\title{
Utilization Of Mobile Phones To Apply Blended Learning At Higher Education: Computer Subject at State Vocational High School 1 BENGKULU
}

\author{
Paidi $^{1}$, Basuki Wibawa ${ }^{1^{*}}$ \\ ${ }^{1}$ Educational Technology, Universitas Negeri Jakarta, Indonesia \\ *Corresponding author E-mail: basukiwibawa@unj.ac.id
}

\begin{abstract}
The application of blended learning at vocational high schools is one of the solutions to increase interest in learning to students. The preparation of software is easily accessible on gadgets, thus the delivery of material can be done online. Tasks and practices may be applied in class according to teacher's instruction. By data in the form of the amount of gadgets used by students reaching 100 percent, the delivery of material by video, voice recordings to learning materials can be received easily. The task and practice plan project is delivered at the beginning of lesson with targets determined in accordance with the applicable curriculum. By applying the blended learning method by utilizing gadgets, it can be one alternative for developing and increasing interest in learning to students.
\end{abstract}

Keywords: Educational technology, Handphone, blended learning.

\section{Introduction}

For the last on decade, internet usage and internet-based gadgets are very common among students [1]. This process indirectly contributes to the development of children both in social life and education [2-10]

The use of mobile phones as one of the suggestions for learning to improve learning achievement has been developed by Rahmah [11]. In her study, increasingly sophisticated mobile technology can influence student's behavior on education. However, the development of mobile technology can be used as a means of developing educational technology [12-17]. Zang et al. [18] stated teaching in conventional ways becomes increasingly unpopular in the 21 st century. It will develop into mobile learning that can be easily accessed by students.

Chia et. al [12] stated virtual learning developed is able to collaborate some activities both research and discussion from several teams among countries at one time. Thus, the utilization of virtual learning gives a positive aspect to cognitive aspect of students. However, crucial factors in education and the tools needed must be in accordance with the learning objectives of using mobile learning [19]. This is in line with the research conducted by Dessy Harisanti and Esty Putri Anugrah [20], where a manual learning model by reading in the library from textbooks has decreased in interested persons. From the facts found, library is even used as discussion or other purposes. This is different from the assumption that library is used to borrow books or read popular things.

In Indonesia, the last few years have developed more vocational education compared to general types of education, this is in line with the government program that graduates from vocational education can be projected as graduates who are ready to work.

The characteristics of vocational education at the middle level shows giving practice has a larger portion compared to theory. This applies to all existing lessons. This is in accordance with the analysis made by Suryo Hanrtano and Ratih Fordina [...] in researching the needs of high vocational education on chemistry subject. In their research, the chemistry curriculum for high vocational education has similarity compared to higher education (university) in general. Thus, with the demand that every graduate from vocational education is able to work and has a scientific foundation, the addition of practice portion must be enlarged compared to theoretical proportion, making certain difficulties for vocational education providers.

According to Moodie [21], vocational education generally aims at: (1) creating productivity for graduates independently. This can be assumed to be able to create jobs independently, (2) selfpreparation to meet carrier demands in accordance with the field studied, (3) being able to develop and use technology in each vocational education graduate, (4) forming graduates' competencies in accordance with the needs of workforce and being able to compete with industry needs.

From some of the above researches, the burden of vocational education both at junior and high levels of learning has become increasingly complex. Based on the fact that the use of gadgets is increasing and in accordance with the topic of computer subjects that interact more with technology, in this research the author provides an alternative using mobile phone to apply a learning model for blended learning on computer subject at vocational high school in Bengkulu.

\section{Method}

One of the criteria for success in the teaching and learning process is that it can be well-received and applied by students. In addition, the assessment result of the test provided also increases along with the increase in the knowledge of the student. Some methods have been implemented to increase students' interest and learning 
achievement in students, among others applying blended learning. However, this method must be supported by appropriate resources. The requirements for learning process using blended learning include

1. supporting facilities, interactive room, internet, software (website)
2. learning concept adapted to the blended learning method

3. clear target learning achievement and student abilities in accessing communication media

4. continuous evaluation

In this study, the use of mobile phones as one of the learning media can be done with the following steps (figure 1)

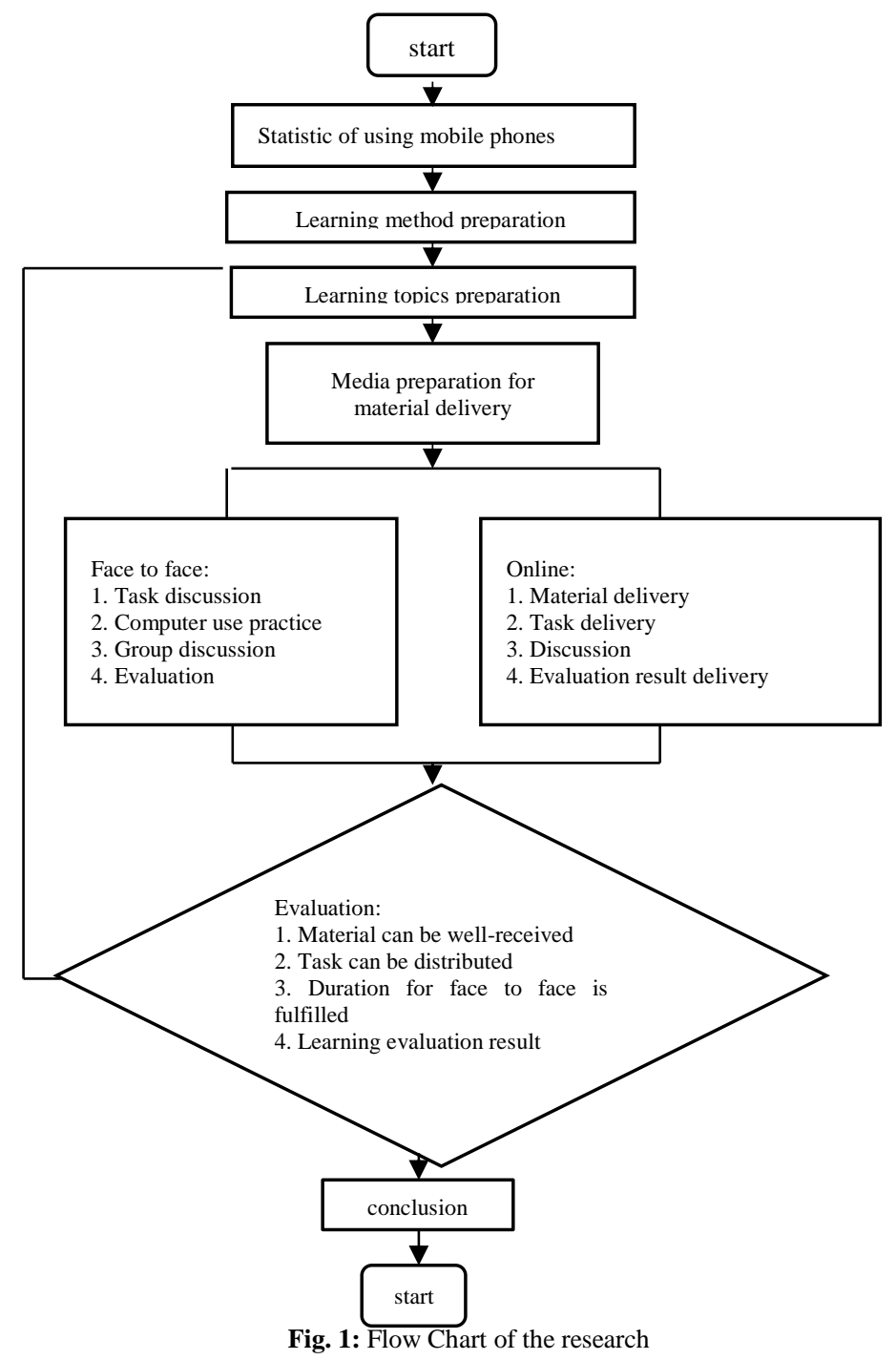

In this study, the application of this learning model is applied to one class as a pilot, with the number of students is 56 where $100 \%$ of them have android-based mobile phones. This data is the basis for the application of the blended learning model using hand phone as a suggestion for student learning.

Next, the author collects data using hand phone for social interaction and which applications are favorite. The purpose of collecting this data is to find out the means of delivering subject in the form of theory before the class meeting is conducted (face to face). In order to find out the application that becomes the students' favorite, the percentage of material delivery will be greater.

After finding out the media often used by students, preparation of learning method by arranging face-to-face proportion and online material delivery can be done. This is also accompanied by material preparation and topics to be delivered to students.

After the material and topics are adjusted to the curriculum on computer lesson for vocational high school, the material delivery by a face to face model is conducted for discussion topics, computer use practices, group discussion and evaluation. Meanwhile, virtual submission is done for theoretical material, individual assignments, general discussion and evaluation on material delivery.
Study material delivered to students is adapted to the existing curriculum. Next, a part that requires a direct interaction between teachers and students (face to face) and the material that can use an online model with the students are selected. The social media commonly used by students are Facebook, Instagram and WhatsApp as support in the learning process. Uploading the syllabus and lesson material on websites, face-to-face schedules, group discussions and joint tasks are done in a structured manner. To measure the success of the learning model applied to computer subject in vocational high school students in Bengkulu is done by summing up website visitors (students who have downloaded the subject, assignment material and discussion material on the website provided as learning tools).

\section{Result and Discussion}

In applying gadget-based blended learning, gadget user data is needed. When all students know and are familiar with the use of gadgets, the use of positive things are, among others, to facilitate the material delivery that is very useful. Although it cannot be avoided, there is a negative effect in the form of content that is irrelevant to the world of education. 
According to the data, of 56 students the average time needed for interaction with mobile phones and gadgets as a means of interacting with social media is as follows

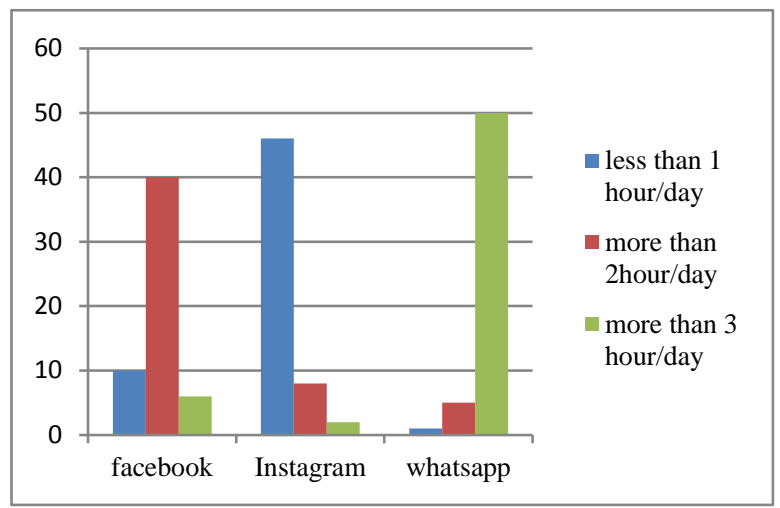

Fig. 2: Chart of time using mobile phones to interact by social media.

Whereas based on the applications available on mobile phones (Table 1), the following are favorite applications accessed by students.

Table 1. Favorite application accessed by mobile phone users

\begin{tabular}{ccc}
\hline No & Name of application & Accessed every day \\
\hline $\mathbf{1}$ & Whatsapp & More than 30 times \\
$\mathbf{2}$ & YouTube & More than 10 times \\
$\mathbf{3}$ & Facebook & More than 10 times \\
$\mathbf{4}$ & Music application & More than 3 times \\
$\mathbf{5}$ & Games & More than 2 times \\
$\mathbf{6}$ & Email & Once \\
\hline
\end{tabular}

From the above data, whatsapp is a social media that is very popular among students with daily access intensity of more than 30 times per day. While YouTube and Facebook rank the second, accessed by more than 10 times per day and the following is music and games accessed by more than once at average per day. This presents a challenge for the application of blended learning which in fact requires an active interaction between students and the use of online media.

Next, software (website) preparation for the blended learning method on computer subject can be done as shown in Figure 3.
The students can download materials or topics, in the form of explanation, slides, videos and tutorials easily and be adjusted to the schedule. However, in practice, this process is not always linear with the students' interest in following and interacting with computer subjects. And it is proven by the lack of access to the website provided.

To support the success of gadget-based blended learning, the distribution of Syncron and the Asyncron can be adapted to the curriculum for vocational schools, as presented in table 2 below

Table 2. the application of blended learning on computer subject

\begin{tabular}{|c|c|c|c|}
\hline no & $\begin{array}{l}\text { Learning } \\
\text { Modality }\end{array}$ & Syncron & Asyncron \\
\hline 1 & Read Material & & $\sqrt{ }$ \\
\hline 2 & Hear Material & & $\checkmark$ \\
\hline 3 & See Tutorial & & $\checkmark$ \\
\hline 4 & Demonstration & $\checkmark$ & \\
\hline 5 & Practice & $\checkmark$ & \\
\hline 6 & Discussion & $\checkmark$ & \\
\hline 7 & Review & $\checkmark$ & $\checkmark$ \\
\hline
\end{tabular}

For the asyncron model, only relying on the student's willingness to the website provided does not guarantee the effectiveness of delivering the material, while by utilizing the applications on the mobile phone, information about the latest material, tutorials or tasks can be improved. The use of other applications can be seen as shown in the following Table 3 .

Table 3 The use of applications in mobile phones to deliver material and information on computer subject

\begin{tabular}{llcccc}
\hline No & Curriculum & $\begin{array}{c}\text { Websit } \\
\text { e }\end{array}$ & $\begin{array}{c}\text { Whatsap } \\
\text { p }\end{array}$ & Facebook & Instagram \\
\hline $\mathbf{1}$ & Course & $\checkmark$ & $\checkmark$ & & \\
& Material & & & & \\
$\mathbf{2}$ & Tutorial & $\checkmark$ & $\checkmark$ & $\checkmark$ & \\
$\mathbf{3}$ & Practice & $\checkmark$ & & & \\
$\mathbf{4}$ & Task & $\checkmark$ & & $\checkmark$ & $\checkmark$ \\
$\mathbf{5}$ & Demonstration & $\checkmark$ & $\checkmark$ & $\checkmark$ & \\
$\mathbf{6}$ & Discussion & & $\checkmark$ & & \\
$\mathbf{7}$ & Examination & $\checkmark$ & & & \\
\hline
\end{tabular}

When the material has been delivered on the website, notice can be given by using Whatsapp or Facebook or other supporting media.

When discussion is required to solve problems together, Facebook media can also be utilized (figure 4).

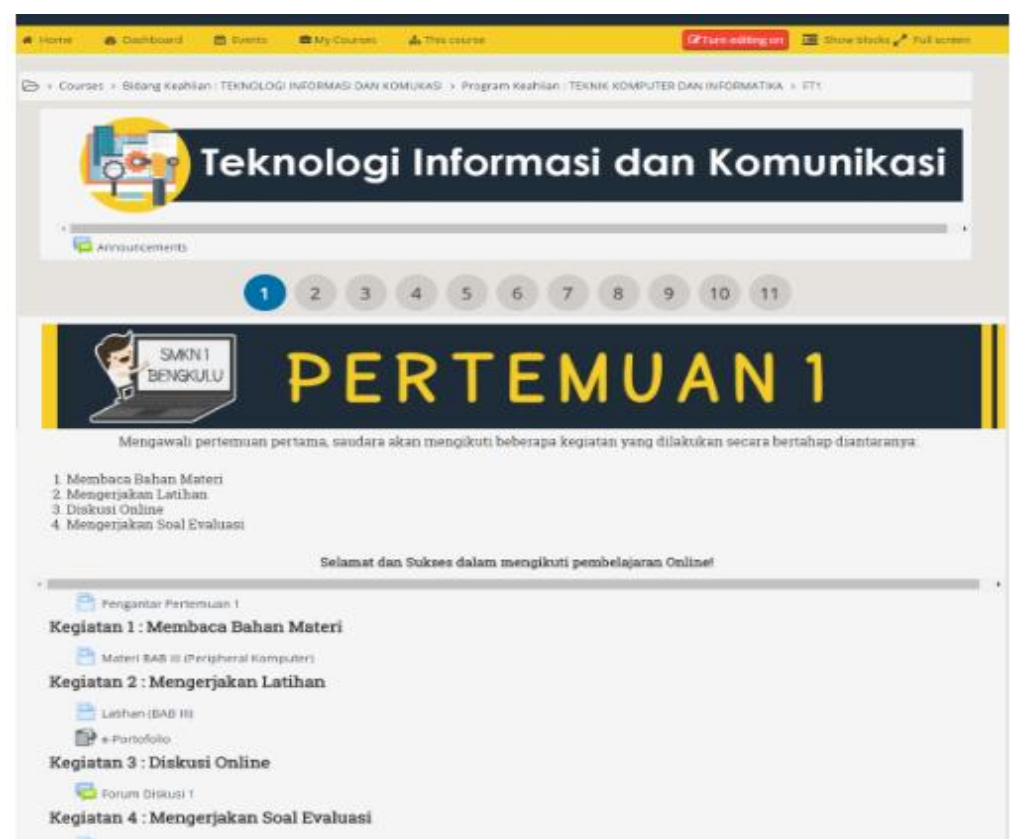

Fig. 3 Website for computer subject. 


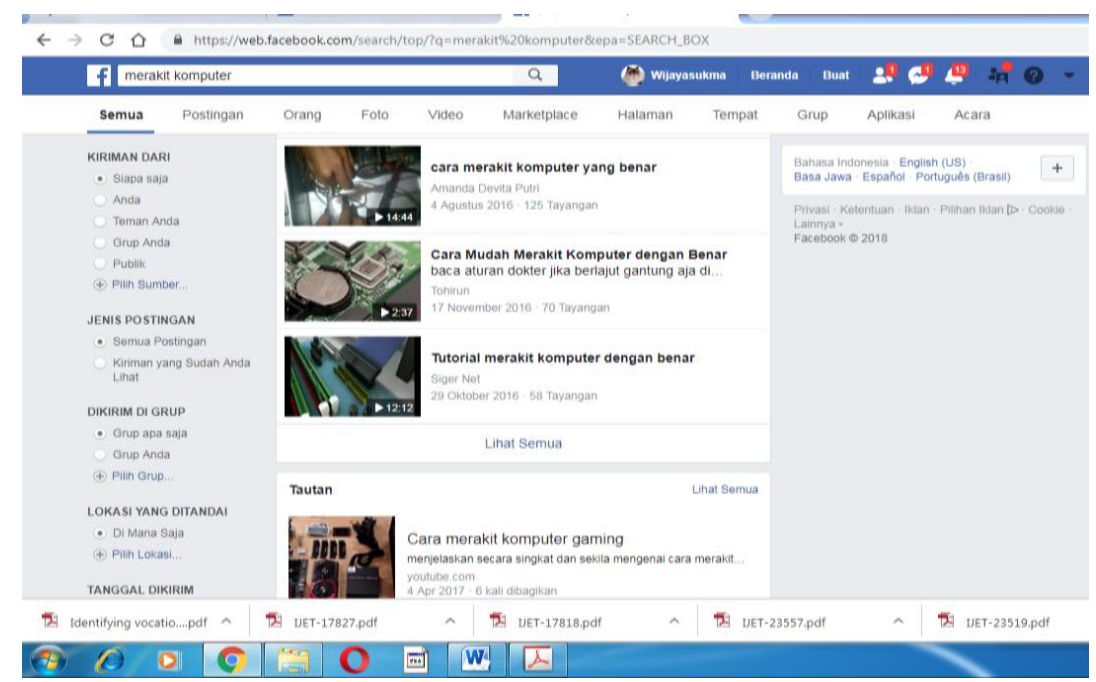

Fig. 4 the use of Facebook media to support the delivery of computer subject information.

Meanwhile, face to face method can be used as a medium for discussion and problem solving.

After the material delivery and announcement through Whatsapp and Facebook media, Face to Face for discussion to solve problems and practices are also used to evaluate the effectiveness of the material delivery. By calculating the amount of access to the web provided, the announcement of the media on mobile phones increases the amount of access to the website on computer subject as shown in Figure 5 below.

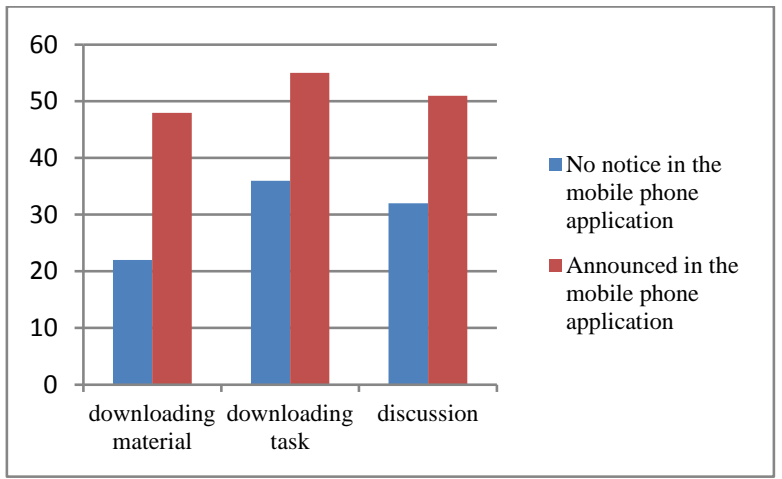

Fig. 5: The increase in the number of web access and material downloading

There are 3 significant improvements in the student activities: the intensity of students downloading material as provided by the teacher on the website initially done without the use of mobile phone was $42 \%$, but after the use of media, the result of the material downloading increased by $87 \%$. Hence, they did the tasks given for computer subject. As for the discussion, the use of application on the handset becomes very helpful. When discussion is only done on the web provided, students are not enthusiastic to participate. Whereas when using application on mobile phone to encourage students, the level of participation in the discussion incerased up to $96 \%$.

\section{Conclusion}

By applying blended learning supported by Mobile Technology, in vocational high schools it provides benefits to increase interest in learning. $30 \%$ theory and $70 \%$ practice to form vocational high school graduates who are ready to work can be done well. Students can actively find out the material, tasks and invitations to discuss something occured to the lesson. In addition, communication that occurs from students to teachers becomes more effective.
The use of social media as a means of supporting learning in addition to the website already provided for computer subjects in vocational high schools in Bengkulu, is proven to increase students' learning skills shown by an increase in the number of theories delivered. The average character of vocational high school students provides a smaller portion of learning skills compared to their practices.

\section{References}

[1] A. Rahim, S. Z. Safin, L. K. Kheng, N. Abas, and S. Meriam, "Factor Influencing Purchasing Intention of Smartphone among University Student," Procedia Economic and Finance, vol. 37, p. 9, 2016.

[2] D. Matukhin and E. Zhitkova, "Implementing Blended Learning Technology in Higher Professional Education," Procedia - Social and Behavioral Sciences, vol. 206, pp. 183-188, 2015.

[3] A. L. Nazarenko, "Blended Learning vs Traditional Learning What Works_(A Case Study Research)," Procedia - Social and Behavioral Sciences, vol. 200, p. 6, 2015.

[4] A. A. Okaz, "Integrating Blended Learning in Higher Education," Procedia - Social and Behavioral Sciences, vol. 186, pp. 600-603, 2015.

[5] N. A. Shukor, Z. Tasir, and H. Van der Meijden, "An Examination of Online Learning Effectiveness Using Data Mining," Procedia Social and Behavioral Sciences, vol. 172, pp. 555-562, 2015.

[6] S. Wongwanich, C. Piromsombat, P. Khaikleng, and K. Sriklaub, "Policy Delivery Strategies for Education Reform: A Formative Research and Development," Procedia - Social and Behavioral Sciences, vol. 171, pp. 1365-1372, 2015.

[7] M. Clement, L. Vandeput, and T. Osaer, "Blended Learning Design: A Shared Experience," Procedia - Social and Behavioral Sciences, vol. 228, pp. 582-586, 2016.

[8] A. BakarNordin and N. Alias, "Learning Outcomes and Student Perceptions in Using of Blended Learning in History," Procedia Social and Behavioral Sciences, vol. 103, pp. 577-585, 2013.

[9] S. Aydin, Y. Akkan, E. Arpaz, and B. Koparan, "Online Learning in Vocational School: Focus on Students' Perceptions," Procedia Social and Behavioral Sciences, vol. 174, pp. 3663-3667, 2015.

[10] A. T. Baharin, H. Lateh, H. m. Nawawi, and S. S. Nathan, "Evaluation of Satisfaction Using Online Learning with Interactivity," Procedia - Social and Behavioral Sciences, vol. 171, pp. 905-911, 2015.

[11] A. Rahmah, "Digital Literacy Learning System for Indonesian Citizen," Procedia Computer Science, vol. 72, pp. 94-101, 2015

[12] H. P. Chia and A. Pritchard, "Using a virtual learning community (VLC) to facilitate a cross-national science research collaboration between secondary school students," Computers \& Education, vol. 79, pp. 1-15, 2014.

[13] J. K. Law, P. A. Thome, B. Lindeman, D. C. Jackson, and A. O. Lidor, "Student use and perceptions of mobile technology in clinical clerkships - Guidance for curriculum design," Am J Surg, vol. 215, pp. 196-199, Jan 2018. 
[14] N. Kälberer, B. Petendra, C. Böhmer, A. Schibelbein, and E.-M Beck-Meuth, "Evaluation Process and Quality Management in a Blended-learning Bachelor's Programme," Procedia - Social and Behavioral Sciences, vol. 228, pp. 131-137, 2016.

[15] G. Kofar, "A Study of EFL Instructors $\square$ Perceptions of Blended Learning," Procedia - Social and Behavioral Sciences, vol. 232, pp. 736-744, 2016

[16] T. Markova, I. Glazkova, and E. Zaborova, "Quality Issues of Online Distance Learning," Procedia - Social and Behavioral Sciences, vol. 237, pp. 685-691, 2017.

[17] R. Soler, J. R. Soler, and I. Araya, "Subjects in the Blended Learning Model Design. Theoretical-Methodological elements," Procedia - Social and Behavioral Sciences, vol. 237, pp. 771-777, 2017.

[18] B. Zhang, C.-K. Looi, P. Seow, G. Chia, L.-H. Wong, W. Chen, et al., "Deconstructing and reconstructing: Transforming primary science learning via a mobilized curriculum," Computers \& Education, vol. 55, pp. 1504-1523, 2010.

[19] N. Nordin, M. A. Embi, and M. M. Yunus, "Mobile Learning Framework for Lifelong Learning," Procedia Social and Behavioral Sciences, vol. 7, p. 9, 2010.

[20] D. Harisanti and E. P. Anugrah, "Characteristics of Senior High School Student in the Utilization of School Library in Indonesia," International Journal of Engineering \& Technology, vol. 7, p. 5, 2018.

[21] G. Moodie, "Identifying vocational education and training," Journal of Vocational Education and Training, vol. 54, p. 19, 2002. 